\title{
Pensar a la intemperie: \\ LA CRÍTICA EXPUESTA AL RIESGO DE LA EXPERIMENTACIÓN \\ http://dx.doi.org/10.1590/1984-0292/1326
}

Eduardo Pellejero ${ }^{\star}$

Universidade Federal do Rio Grande do Norte, Natal, RN, Brasil

\section{RESUMEN}

La experimentación en arte constituye un objeto refractario para la crítica, que ve sus categorías cuestionadas, desbordadas por la propia naturaleza de su objeto. Más allá de las formas consagradas de la historia del arte, el crítico que se aproxima de la experimentación artística es aquel que, sin reservas, pone a prueba la cultura, abriéndose a la multiplicidad de sus sentidos y a la imprevisibilidad de sus pulsiones. El presente trabajo pretende explorar las tensiones que, al nivel de la experiencia estética, la experimentación produce en nuestras subjetividades, a instancias de su apreciación, su interpretación o su crítica.

Palabras Clave: experimentación; crítica; experiencia estética; arte contemporânea.

\section{THINKING OUTSIDE:}

\section{THE CRITICISM EXPOSED TO THE RISK OF EXPERIMENTATION}

\begin{abstract}
Experimentation in arts constitute a refractory object for critics, whom see their concepts in question. Beyond the consecrated forms of history of art, their philosophical presuppositions and academic compromises, any critic that approaches artistic experimentation tests the culture of his time, exposing his subjectivity to the multiplicity of senses and the drives of his desire, without preconceived ideas of any kind of knowledge, truth or reason to conquer. This paper aims to explore the tensions that, at the level of aesthetic experience, are produced in our subjectivities every time we appreciate, interpret or critic experimental art.
\end{abstract}

Keywords: experimentation; critics; aesthetic experience; contemporary art.

\footnotetext{
^Endereço para correspondência: Universidade Federal do Rio Grande do Norte, Centro de Ciências Humanas Letras e Artes. Campus Universitário, km 1, BR 101 - Lagoa Nova. 59078970 - Natal, RN - Brasil.E-mail: edupellejero@gmail.com
} 
En esa intemperie que, lo repito, es la de todos los hombres, pero de la que yo quiero, no sé por qué, sacar textos, ha de comenzar, a mi juicio, el trabajo de narración. (SAER, 2004, p. 145)

Cuando, en 1964 Harold Rosenberg hacía el balance de las dos últimas décadas de arte norte-americana, y constataba con inquietud la aceptación masiva de las vanguardias, la institucionalización y oficialización de la rebeldía (ROSENBERG, 2004, p. 16), tenía en mente un concepto de experimentación que excedía las fragilizadas figuras que le dieran cuerpo históricamente. El rechazo de soluciones superficiales y fraudulentas, el cuestionamiento del papel del arte en relación al conjunto de las actividades humanas, y la incorporación de la libertad del artista para redefinir el significado de su práctica, delineaban el sentido filosófico de la experimentación y, en esa medida, comportaban una disposición anímica fundamental: la ansiedad.

Cuarenta años más tarde, proveniente de otro contexto, pero ante el mismo problema, Juan José Saer escribía (2006, p. 187, las cursivas son nuestra):

Una opacidad inédita caracteriza cada etapa de la sociedad. Adoptar, por conveniencia o estupidez, una ideología de compromiso, por evidente y rentable que parezca, no alcanzará para ocultar un hecho capital: para cada nueva generación la pregunta acerca de la razón de ser y de la manera en que se forja el arte, semejante a una llaga, seguirá abierta. ${ }^{1}$

En la medida en que se presenta como una escena de libertad sin determinación, en la medida en que constituye un espacio de variación continua y de rechazo de las formas establecidas, en la medida en que comprende "la constante revisión de sus objetivos, de sus técnicas y de su finalidad" (ROSENBERG, 2004, p. 22), la experimentación en el arte constituye un objeto refractario para la crítica, que ve sus categorías cuestionadas, desbordadas por la propia naturaleza de su objeto.

También no es una presa fácil para la filosofía. Después de todo, ¿qué es la experimentación? Quiero decir: ¿es así tan evidente que podemos considerarlo un objeto del pensamiento crítico? En cuanto intentamos una primera aproximación, el carácter filosóficamente elusivo de la experimentación nos obliga a introducir algunas oposiciones programáticas, esquemáticas, incómodas; nos obliga a postular perspectivas diferenciales: actitudes antagónicas o momentos sucesivos, o incluso dimensiones coexistentes en el seno de las prácticas artísticas. Distinciones metodológicas, en principio, pero sin las cuales la propia noción de experimentación parece diluirse en una noción genérica de arte.

Hechas las debidas reservas, en todo caso, y siendo que constatamos que no todas las manifestaciones artísticas se dan al trabajo de la experimentación (ni se exponen a la ansiedad consecuente), podemos considerar, por un lado, los artistas que consienten en adecuarse a las divisiones establecidas del arte, o incluso a los géneros que cada territorio artístico comporta, en tanto receptáculos formales más o menos invariables a ser henchidos con contenidos de inteligibilidad más 
o menos consensual: la bidimensionalidad de la pintura o la representatividad social de la novela son figuras de lo primero, el tema de la formación sentimental del artista adolecente o la cuestión de la exuberancia de los pueblos latinoamericanos, del segundo (SAER, 2004, p. 124). Eso no es tan malo como suena: la exploración o revisitación de los territorios conocidos no es necesariamente una forma despreciable del arte - sus imágenes todavía nos interpelan, sus historias nos conmueven, sus harmonías nos tocan, nos identificamos o nos extrañamos con ellas (y consecuentemente la crítica no puede pasar por alto sus alternativas).

Ahora bien, por otro lado, debemos considerar los artistas que, sin una definición estilística clara ni nada especial que comunicar (sin misión histórica alguna, por tanto), se entregan a una exploración - sin reservas - de la lengua o de las formas visibles, del espacio o de la materia sensible, independientemente de cualquier precepto de legibilidad o inteligibilidad, colocando en cuestión (modificando) las funciones instituidas del arte y transgrediendo todo precepto de género, de estilo o de valor. Esos artistas ${ }^{2}$ afirman, a través de su ejercicio, que aquello que identificamos como arte, en una sociedad determinada y en un momento dado, constituye apenas un estadio histórico, un simple momento del devenir de la conciencia, y que, en tanto tal, debe abrirse a figuras imprevisibles, aun cuando todavía puedan carecer de nombre propio, de función específica o de inteligibilidad inmediata. Con una convicción que excede cualquier programa, esos artistas se proponen transgredir los códigos establecidos y los lugares consagrados, las competencias asignadas y los valores atribuidos (eso que Rancière denominará "división de lo sensible"). De la lucidez y el compromiso con la que encaren esa tarea dependerán la sobrevivencia y la renovación de la problemática arte que practican (SAER, 1999, p. 61).

La originalidad [decía Rosenberg] es una consecuencia de la duración de la acción, de la larga experiencia de soportar la ansiedad y persistir. En el transcurso del enfrentamiento, se forja un espíritu. Fuera de eso, toda especie de excelencia puede ser copiada (ROSENBERG, 2004, p. 24).

La esquemática oposición que proponemos retoma libremente un pequeño ensayo de Juan José Saer de 1981 (más tarde incluído en El concepto de ficción (2004)), donde este forzaba hasta la sobreinterpretación un conocido texto de Walter Benjamin (El narrador, 2008[1936]) para caracterizar polémicamente las figuras del narrador y del novelista en el contexto de la literatura contemporánea. Según Saer (2004, p. 274),

[...] el narrador es el que viaja y el novelista es el sedentario, es decir el que instalado en formas que están ya vacías y que no tienen ningún sentido, persiste en permanecer en un lugar histórico que ya no tiene ningún dominio sobre lo real. ${ }^{3}$

Aceptemos provisoriamente esa distinción entre dos tipos arquetípicos, incluso si sólo es posible comprender el devenir de la literatura a partir de su interpenetración (BENJAMIN, 1994, p. 199). El arte en cuanto modo de expresión 
consagrado (independientemente de que comprenda una pluralidad de formas o reclame para sí un continuo de medios) es, antes que nada, el riesgo del sedentarismo, luego, de la tautología o de la conformidad. En el caso de la literatura, la forma de la novela clásica y de su vulgarización bajo las formas del folletín o del best-seller, elevan ese riesgo al paroxismo. En cuanto figura por excelencia de la legibilidad, la novela asegura a sus cultures entrar en la lista de los más vendidos, a sus lectores una experiencia sin sobresaltos, y a sus críticos la oportunidad de una demostración de competencia intelectual. En principio, yo no tengo nada contra la claridad y la amenidad, contra la legibilidad, ${ }^{4}$ pero si no pretendemos abrir mano de la noción de literatura, deberemos conducirla más allá de esa, su figura hegemónica actual, deberemos elevar la novela a la categoría de problema (de forma y contenido). Ahí comienza la experimentación.

Numerosos escritores exploraron y continúan explorando esa otra vía, al mismo tiempo plural y destinada a un fracaso seguro, a un recomienzo perpetuo. Ellos exponen la literatura a una forma de riesgo inconmensurable: el riesgo del error, de la pérdida de los territorios conquistados pero también de cualquier pretensión de verdad, como decía Blanchot ${ }^{5}$ (riesgo, por tanto, de impropiedad y de impostura); o, como por su vez traducirá Foucault, el riesgo, continuamente retomado y asumido para cada palabra, para cada frase, y para cada obra, de no obedecer a los códigos lingüísticos, a los géneros literarios, a las categorías críticas, a los hábitos de lectura, a las tendencias del mercado (riesgo, por lo tanto, de un lenguaje privado, impenetrable, inaccesible).

Tal vez la experimentación no sea otra cosa que ese extrañamiento del arte en relación a sí misma (a sus figuras históricas, a los regímenes de su identificación). Y, en el caso de la literatura, ese extrañamiento implica la afirmación de la soberanía de la palabra literaria, la restitución del desequilibrio del lenguaje y la recuperación de misterio de las cosas. ${ }^{6}$ Diríase que por vía de la experimentación los artistas de alguna forma se instalan en el futuro, o, mejor, en un tiempo propio, acrónico, anacrónico, y desde ese lugar extemporáneo trabaja el presente con los espectros de lo que todavía no es, conduciéndonos más allá de lo que nos es familiar (evidentemente, de ahí no se regresa, o no se regresa nunca de la misma forma). La experimentación es para ellos un correlato de la necesidad de volver a poner en juego el suelo de certezas y el horizonte de expectativas que presupone toda arte: es la "negantropía del saber" (de nuevo Foucault), el especio mínimo necesario para que las prácticas artísticas y las miradas que se proyectan sobre sus obras puedan manifestar nuevamente (una vez más) su dependencia de nuestros apuestas imaginarias y existenciales, intelectuales y políticas.

Quizá nadie haya planteado recientemente la cuestión de esos dos riesgos antagónicos a los cuales se expone el arte mejor que Enrique Vila-Matas, a quien quisiera convocar en calidad de crítico, incluso si sus textos tienden a ser acomodados en los estantes de la ficción (porque la crítica también puede abrirse a la experimentación y barajar las categorías establecidas que la definen desde la ilustración). 
En Chet Baker piensa en su arte, un pequeño texto de 2011, la confianza en las estructura de la narración novelesca es expuesta por Vila-Matas a los embates de las poéticas que afirman la opacidad de lo real, esto es, confrontada con el linaje de los Finnegans, ${ }^{7}$ esa rara estirpe de escritores que oponen los requiebres de una escritura hermética y refractaria al sentido a la ingenuidad de la narratividad propia de las poéticas de la representación (y el linaje de los Hires), ${ }^{8}$ afirmando una literatura que pretende relacionarse con la verdad de la vida incomprensible, oponiendo, al orden ficcional de los acontecimientos y a la confianza ciega en el poder significante del lenguaje, una palabra solidaria del carácter caótico de la realidad y de esa vaga fluctuación de nuestras vidas de la que hablaba Kafka, esto es, de la existencia bárbara, muda, sin significado, de las cosas.

El mundo - alude Vila-Matas (2011, p. 245), pero quien habla es Musil -, el mundo ya no se adecúa al orden narrativo de la novela, a la simple e ilusoria sucesión de los hechos, siendo necesario explorar nuevas formas de escritura, que se relacionen mejor con la ambigüedad de lo real y la imprevisibilidad del vida. Es verdad que Vila-Matas afirma no querer resignar las formas narrativas clásicas, abrir mano de ellas, pero en la tentativa de establecer un compromiso entre ambas poéticas (Finnegans con rostro de Hire), buscando abrir espacio para la novela del futuro, quizá acaba por destruir definitivamente la forma genérica a la que se aproxima (de lo cual la totalidad de su obra es un buen ejemplo). ${ }^{9}$ Evidentemente, la historia de la novela es, desde sus orígenes, la historia de una revuelta constante contra los hábitos contraídos por la propia novela: la exploración y la transgresión de sus fronteras siempre estuvieron asociadas a su juego. Pero las poéticas que exploran los límites de la representación clásica no pueden dejar de chocar con las formas establecidas de la novela: encarar la opacidad de lo real, su esencial ilegibilidad, es poner en cuestión la novela en cuanto figura de la narración y, en esa medida, debería necesariamente dar lugar a nuevas formas, a nuevas experiencias literarias.

La experimentación asume esa posición incómoda de la conciencia, que por otra parte es común a críticos y artistas - de Mallarmé a Valéry, de Joyce a Borges, de Kafka a Benjamin, y de Becket a Deleuze. ${ }^{10}$ Después de todo, las formas de la crítica también se encuentran expuestas al devenir de la conciencia (razón por la cual deberíamos desconfiar de las fronteras que se establecen entre ella y sus objetos, así como de sus formas consagradas). Si hay algo que no cambia, que no puede cambiar, al menos en su filiación moderna, es quizá lo siguiente:

1) La crítica ofrece una especie de suplemento conceptual a las obras: las identifica o presenta como formas de arte, nos invita a una forma de consideración de esos objetos que no se parece a las formas en las cuales consideramos cotidianamente los objetos. En ese sentido, la crítica es un momento de reconocimiento o, mejor, de resignificación. Una suerte de llamada de atención. Así, por ejemplo, la fotografía surge como un procedimiento técnico-científico para análisis del movimiento, hasta que por la intercesión de la crítica es desplazada para un escenario que no se dejaba prever: el de las imágenes del arte. Del mismo modo, las experimentaciones modernistas muchas veces

Fractal, Rev. Psicol., v. 26 - n. esp., p. 509-522, 2014 
necesitaron de la intercesión de la crítica para ser consideradas como pertenecientes al dominio del arte y no, por ejemplo, al de la perturbación mental (Antonin Artaud, Daniel Johnston), de la infancia (Henri Rousseau, Joan Miró), etc.

2) La crítica amplía y complica el mapa de la sensibilidad. Tiene por objeto abrir la mirada, espaciar la lectura, presentar un abanico de posibilidades para la interpretación, hecho de visibilidades, significaciones, alusiones y conceptos no evidentes. Consiste, en ese sentido, en una forma de iluminación, que no pretende agotar el sentido de las obras (sentido que sólo depende de cada encuentro con el espectador), pero que puede conducirnos mucho más allá de lo que a primera vista podríamos creer. Entonces la crítica es un movimiento que nos hace reparar en lo que, en principio, podría pasarnos por alto, y, en ese sentido, es un auxilio precioso. Toda obra es incompleta, inacabada, abierta; exige, en esa misma medida, una mirada activa, una lectura colaborativa que, sin cerrarla, desenvuelva todas sus potencialidades, entre en un dialogo. Tal es el objetivo de la crítica.

3) La crítica traba una relación muy especial con la actualidad: "de la vasta, intrincada herencia del pasado la crítica traerá a la luz y promoverá aquello que habla al presente de un modo especialmente directo y apremiante" (STEINER, 2003, p. 23). El crítico debe elegir, y su elección debe privilegiar lo que puede entrar en diálogo con los vivos. Cada generación hace su elección. Hay obras que van más allá de su tiempo, pero la crítica cambia de época para época, está atada al presente. Comparada con la creación artística, la crítica puede parecer secundaria, pero en la época en la cual nos toca vivir, bombardeados por cantidades no manejables de información, sofocados por la multiplicación de los archivos, desvelados por el acceso permanece a todo lo que ya fue hecho, gana un valor fundamental, rescatando unas pocas cosas del olvido, proponiéndolas a nuestra atención como elementos fundamentales para pensar lo que somos, lo que llegamos a ser, pero también lo que estamos en vías de transformarnos. El crítico es, en ese sentido, una especie de viajante de comercio. Propone una colección, un recorte, antes de cualquier interpretación. Lleva consigo, y somete a nuestra consideración, una especie de museo o biblioteca portátil. Las referencias más obvias de esa metáfora se encuentran en la tradición va de Duchamp a Vila-Matas, pero conoce una serie de practicantes inesperados que exceden las definiciones académicas de la crítica (por ejemplo, Henri Miller y los libros de su vida) y de teóricos eclécticos (por ejemplo, Barthes y el concepto de colección). Así, por ejemplo, Jorge Luis Borges en cuanto crítico es aquel que propone un corpus literario heterodoxo, que reúne autores que "no se parecen entre sí", en orden a dar espacio a una literatura por venir (la suya, pero no sólo). Por su vez, a través de un gesto similar, pero diferido, Ricardo Piglia ejerce la crítica subvirtiendo 
ese corpus y proponiendo otro: algunos de los autores borgeanos permanecen, otros (muchos) cambian - la historia de la literatura sigue siendo la misma, pero los problemas con los cuales se depara la crítica son inconmensurables, solidarios de las fuerzas que dan forma al presente (o lo colocan en causa).

4) La crítica está lejos de ser relativa. Es la traducción de un descubrimiento. Ciertamente, cada quien hace su experiencia de las obras de arte, y en ese sentido la experiencia de la crítica no es menos subjetiva que cualquier otra. Pero hay en la proposición de la palabra crítica sobre el arte una estructura muy especial, que busca deshacer la distancia que va de la subjetividad a la intersubjetividad. Sabemos que Kant ya apostaba a la experiencia estética la realización de esa travesía. En el mismo sentido apuntado por Kant, la crítica no dicta que un objeto pertenece al arte, no decide su cualidad o determina su significado; simplemente lo propone a nuestra apreciación en cuanto arte, con más o menos entusiasmo, y sugiere recorridos para nuestra mirada. Es la traducción de una aventura intelectual singular, subjetiva, pero que espera encontrar en los otros, en aquellos a los cuales dirige su palabra, un eco, una resonancia. Podemos aceptar su invitación (o no), podemos compartir su entusiasmo (o no), podemos recorrer sus caminos (o no). En todo caso, cuando lo hacemos, cuando prestamos libremente nuestro consentimiento, cuando la invitación de la crítica encuentra en nosotros, como correlato, una experiencia productiva, que puede incluso ir más allá de lo sugerido por la crítica, entonces la subjetividad de la crítica abandona el terreno de la relatividad a la cual parece a primera vista condenada, estableciendo puentes entre ella y nosotros, en un movimiento de proporciones inimaginadas. Así, por ejemplo, Octave Mirbeau descubre a Van Gogh en 1891, en una época en la cual el público en general ignoraba su obra y los demás pintores modernistas guardaban poca consideración por él (Cezánne, por ejemplo, creía que Van Gogh pintaba como un loco, y no había en eso un elogio); Mirbeau vio lo que nadie más vio en su época y escribió sobre su experiencia (extremadamente personal, única), algunos leyeron sus textos y comenzaron a ver, algunos de ellos (muchos) escribieron a su vez, y así; hoy la pintura es para nosotros inimaginable sin Van Gogh. Cincuenta años más tarde, Clement Greenberg es tocado por la obra de Pollock de una forma singular e intensa, que lo aísla en su época (todo el mundo estaba más interesado en el realismo americano, en Hopper, por ejemplo); no desconfía de su experiencia, que es intensa, y comienza a escribir una serie de artículos sobre la action painting y el expresionismo abstracto que Pollock exploraba en su atelier: su palabra pasa de persona en persona, como una conjura, hasta que la obra de Pollock no es apenas reconocida como artística, sino como la expresión más elevada de la pintura norte-americana de la época. En el cine, los críticos de 
los Cahiers de Cinema - François Truffaut, Jacques Rivette, Claude Chabrol - descubrieron en los años sesenta el cine norte-americano, de Alfred Hitchcock a Howard Hawks, considerado hasta entonces una mera forma de entretenimiento, y lo elevaron a la categoría de las obras de arte, comparando su películas a la Ilíada y la Odisea, abriendo espacio para una experiencia diferente (más rica, más intensa) de esas poéticas cinematográficas que se tornarían "objeto de culto" en las siguientes décadas. ${ }^{11}$

5) La función de la crítica comprende necesariamente un componente pedagógico y emancipador, y traba una lucha constante contra todas las formas de "tutoría" e "iliteracia", contra la alienación y el embotamiento de nuestras competencias para ver y apreciar, para leer e interpretar, para experimentar y traducir lo que vemos, leemos e interpretamos (y es sólo en ese sentido, pienso, que nos interesa la crítica). ${ }^{12}$ La crítica debe presentar las obras, debe explicar más o menos su significado o sus significaciones posibles, pero también debe animar al público a permanecer ante ellas, a preguntarse por el significado que podrían tener esas obras en su vida, destruyendo, si es necesario, todas las interpretaciones de esas obras - esto es, propiciar el disenso. La crítica no es una mediación entre la obra y el espectador, sino una tentativa de poner las obras a trabajar (a funcionar), debe hacer entrar los espectadores en el juego (sin reglas) de la experiencia estética. En esa medida, la crítica debe ofrecernos todo el saber posible sobre las obras, para luego invitarnos a confrontarnos con la ignorancia que suscita la experiencia "cara a cara" de una obra de arte. En ese lugar entre el saber y la ignorancia, la crítica debe dejarnos a solas; en última instancia, la emancipación es necesariamente un proceso que cada uno debe llevar adelante por cuenta propia.

6) Por fin, la crítica es solidaria de las aventuras de la invención que llevan el arte a recorrer los caminos de la experimentación. Titubeante, temeraria, imprudente a veces, la crítica presupone una renuncia de los atajos conceptuales, el rechazo de las fórmulas fáciles, de los métodos instituidos, ${ }^{13}$ esto es, al saber. La misma reserva que determina la disposición de la experimentación artística en relación a las formas consagradas, y que sitúa al artista en la intemperie, fuerza la crítica a desarmar su mirada, a colocar entre paréntesis, quiero decir a "suspender" todas las estructuras dadas de significación: las categorías y los conceptos que utilizamos para dar una forma al mundo y un sentido a la historia.

La crítica no siempre responde a este último apelo, e intenta racionalizar la ansiedad propia de la ambigüedad de las formas de la experimentación, remitiéndola a un juego cuyas reglas la crítica tendría por objetivo explicitar. Tal es el caso de Will Gompertz (2013, p. 15-16), quien busca inscribir la experimentación en la historia del arte, presentándola como parte de una dialéctica evolutiva que se remonta a los tiempos de Leonardo. Sin embargo, en su singularidad, en su vi- 
talidad, la experimentación implica ruptura, no continuidad; no presupone reglas, ni siquiera las establece, apenas se ofrece a una experiencia que tiene la forma de la interrupción y a un juego desreglado propuesto a nuestra libertad. La remisión del arte a la comprensión, y de la experimentación a algo que debe ser entendido, es una preocupación noble, pero desnaturaliza el sentido de la experimentación y compromete la potencia propia del arte, en la medida en que su práctica tiende a impugnar cualquier conceptuación establecida. En la tentativa de dar derecho de ciudadanía a la experimentación (un lugar en los museos, un espacio en los presupuestos públicos, etc.), Gompertz acaba por inocular la experimentación, esto es, arriesga tornar inocua a la propia arte en su devenir.

Otra actitud crítica es posible, si comprendemos que la experimentación restituye al pensamiento las condiciones que definían la experiencia estética para Kant. ${ }^{14}$ Más allá, o, si prefieren, más acá de las formas consagradas de la historia del arte, de sus presupuestos filosóficos y de sus compromisos académicos, el crítico que se aproxima de la experimentación artística es aquel que, sin reservas, pone a prueba la cultura, abriéndose a la multiplicidad de sus sentidos y a la imprevisibilidad de sus pulsiones, sin ideas preconcebidas de un saber, una verdad o una razón a conquistar. El crítico deviene un fictor, como sugiere Didi-Huberman (2010, p. 13): un hombre mirando para las nubes que se abandona, sin pretensiones, al libre juego de sus facultades.

En otras palabras, la experimentación conmueve los fundamentos del orden del discurso estéticos, que tiende a imponer a los objetos la forma específica de su saber, dando lugar a un pensamiento sin abrigo, expuesto a lo que hay de impensado e inclusive de impensable en el ejercicio tradicional de la crítica (DIDI-HUBERMAN, 2010, p. 14). Eso no significa el rechazo de toda ética del saber, sino apenas la búsqueda de una menos rudimentaria (SAER, 2004, p. 11), ${ }^{15}$ y tal vez un modo de la autenticidad no asociado a la forma de lo verdadero (BLANCHOT, 2011, p. 261). Porque si lo propio de la experimentación y de su crítica es multiplicar las posibilidades de tratamiento de la realidad, las mismas no pueden dejar de sumergirse en su turbulencia, en su ambigüedad, desdeñando la actitud ingenua (luego, dogmática) que consiste en pretender saber de antemano cómo está constituida esa realidad y cuáles son las formas eficaces de su representación (SAER, 2004, p. 11).

La experimentación aproxima así al crítico del artista, en la medida en que en ese periclitante territorio ambos colocan entre paréntesis cualquier estructura de significación existente, cualquier procedimiento consolidado, cualquier inscripción genérica o estilística autorizada, pero también, y sobre todo, cualquier imagen de un objetivo o fin a alcanzar. Rara especie de ceguera, que paradojalmente restituye su sentido profundo al simple gesto de abrir los ojos y ver.

Saer ya advertía que de todas las tentaciones que pueden asombrar al arte y la crítica, la mayor y más peligrosa es creer en las teorías ya formuladas sobre el ejercicio del arte (las teorías que la época propone, incluso si se sitúan en la vanguardia). Y la experimentación no deja de recordarnos que siempre es menos interesante detenerse en los logros, en las conquistas, que escapar de ellas, buscar

Fractal, Rev. Psicol., v. 26 - n. esp., p. 509-522, 2014 
nuevos desafíos, y mantener con alegría la convicción de que, incluso cuando no lleguemos a nada, valen la pena las vueltas de ese camino para la nada que nos propone el arte, porque en algunos de ellos podemos llegar a encontrar aventuras intensas y, quizá, también, formas inesperadas (VILA-MATAS, 2011, p. 253).

Personalmente, no creo que la experimentación deba reclamar para sí la total propiedad del arte (no puede: la historia del arte constantemente se expande para incluir sus descubrimientos). Parafraseando muy libremente algunas bravatas de Roberto Bolaño (2005), yo diría que la experimentación puede habitar de pleno derecho el sótano o la boardilla del arte, y la cocina - ¿por qué no? -, pero no puede ocupar también la sala principal, los cuartas, la fachada. ${ }^{16}$ No es que sea conservador en eso. Por el contrario. Simplemente creo que la experimentación es apenas uno de los momentos de la dialéctica de las prácticas artísticas (y críticas), y que las formas históricas del arte (sus figuras consagradas y sus resguardados secretos) también tienen mucho para decirnos: son un reservatorio casi inagotable de experiencias para nosotros, de experimentaciones más o menos logradas, que pueden llegar a tornarse un verdadero laboratorio si disociadas de los dispositivos historicistas que tienden a sobredeterminar su funcionamiento (Cf. DIDI-HUBERMAN, 2000). En todo caso, para que eso sea (de nuevo) posible, la aventura a la cual nos convida la experimentación es fundamental, y exige toda nuestra atención (y la de la crítica, claro).

William Blake (apud MANGUEL, 2011, p. 22) escribió: “¿Cómo saber si cada pájaro que cruza los caminos del aire no es un inmenso mundo de placer, vedado por nuestros cinco sentidos?". El arte y la crítica siempre vivieron a la sombra de esa intuición asustadora. Y hoy, más que nunca, al margen de la legibilidad total y de la satisfacción garantizada que nos ofrecen las imágenes del mercado, contra el anestesiamiento de nuestra sensibilidad y el alarmante empobrecimiento de nuestro lenguaje en nombre de imperativos de felicidad o rédito 
asegurado, buscan en la experimentación la reconquista de nuestras facultades, quiero decir del misterio del mundo, de la indocilidad de la imaginación, de la agudeza del intelecto, de la libertad.

\section{Notas}

${ }^{1}$ Más cerca de nosotros, Didi-Huberman (2006) define el arte contemporáneo justamente en estos términos: "el arte de cada presente, el arte en cuanto cuestión que está siempre siendo planteada". ${ }^{2}$ Hablamos de una distinción entre artistas, pero la distinción puede ser hecha al nivel de los procedimientos de un mismo artista, o de un movimiento, o de una época. La distinción también puede pasar entre diferentes formas de acogimiento del arte (museológicas, críticas, curatoriales, etc.).

${ }^{3}$ Las categorías deleuzianas, que probablemente Saer no ignorase, dan consistencia a la oposición que la infidelidad hermenéutica para con Benjamin coloca en cuestión.

${ }^{4}$ Roberto Bolaño (2001, p. 173) sí: "Hay una pregunta retórica que me gustaría que alguien me contestara: ¿Por qué Pérez Reverte o Vázquez Figueroa o cualquier otro autor de éxito, digamos, por ejemplo, Muñoz Molina o ese joven de apellido sonoro De Prada, venden tanto? ¿Sólo porque son amenos y claros? ¿Sólo porque cuentan historias que mantienen al lector en vilo? ¿Nadie responde? ¿Quién es el hombre que se atreve a responder? Que nadie diga nada. Detesto que la gente pierda a sus amigos. Responderé yo. La respuesta es no. No venden sólo por eso. Venden y gozan del favor del público porque sus historias se entienden. Es decir: porque los lectores, que nunca se equivocan, no en cuanto lectores, obviamente, sino en cuanto consumidores, en este caso de libros, entienden perfectamente sus novelas o sus cuentos"; "Sigamos, pues, los dictados de García Márquez y leamos a Alejandro Dumas. Hagámosle caso a Pérez Dragó o a García Conte y leamos a Pérez Reverte. En el folletón está la salvación del lector (y de paso, de la industria editorial). Quién nos lo iba a decir. Mucho presumir de Proust, mucho estudiar las páginas de Joyce que cuelgan de un alambre, y la respuesta estaba en el folletón. Ay, el folletón. Pero somos malos para la cama y probablemente volveremos a meter la pata. Todo lleva a pensar que esto no tiene salida" (BOLANO, 2005, p. 26).

${ }^{5}$ El escritor es para Blanchot aquel que, por su sacrificio, esto es, por el sacrificio de la verdad, de la efectividad, de la utilidad de su palabra, nos conduce más allá de lo que nos es familiar.

${ }^{6}$ Cf. FOUCAULT (1994a; 2000)

${ }^{7}$ De Finnegan's wake, de Joyce.

${ }^{8}$ De La novia del señorHire, de Simenon.

${ }^{9}$ Sobre la obra de Enrique Vila-Matas, ver la disertación de maestría de Nadier Pereira (2014).

10 "No hay ficción porque el lenguaje se pone a distancia de las cosas; sino que el lenguaje es esta distancia, la luz donde las cosas están y su inaccesibilidad, el simulacro donde se da su presencia; y todo lenguaje que, en lugar de olvidar esta distancia, se mantiene en ella y la mantiene en él, todo lenguaje que habla de esta distancia avanzando en ella, es un lenguaje de ficción. Puede entonces atravesar toda prosa y toda poesía, toda novela y toda reflexión, indiferentemente" (FOUCAULT, 1994b, p. 280)

${ }^{11}$ Sobre el alcance y los límites de la crítica de los Cahiers, ver: Pellejero (2012).

${ }^{12}$ Cf. RANCIÈRE (2010).

${ }^{13}$ A la historia del arte como disciplina, como "orden del discurso", en tanto condición de ceguera y "voluntad de no ver" y de no saber, diría Didi-Huberman (2000). El tema es retomado de forma especialmente interesante en una entrevista realizada por Potte-Bonneville y Pierre Zaoui a DidiHuberman (2006): "Yo trabajo sólo con singularidades (no tengo nada de general para decir sobre 'el arte', 'la belleza', etc.) en la medida en que las singularidades tienen esa potencia teórica de modificar nuestras ideas preconcebidas, por tanto, de solicitar al pensamiento de una manera no axiomática: de una manera heurística”.

${ }^{14}$ Conocemos la desconfianza de Kant en relación al arte cuando de lo que se trata es de la experiencia estética, pero en la experimentación reconocemos claramente un juego libre de las facultades del artista que presupone una finalidad indeterminada, sin representación de un fin. Es interesante notar que, de esa forma, la doctrina estética kantiana permite incorporar el arte al dominio de la experiencia estética sin la presuposición (pesada) de nociones como la de genio.

15 "Por tanto, la apuesta sería así: saber, pero también pensar el no-saber cuando se desvincula de las redes de saber. Dialectizar. Más allá de su propio saber, adentrarse en la prueba paradojal, 
no de saber (cosa que equivaldría exactamente a negarlo), sino de pensar en el elemento del nosaber que nos deslumbra cada vez que colocamos la mirada sobre una imagen del arte." (DIDIHUBERMAN, 2010, p. 18)

${ }^{16} \mathrm{La}$ casa se vendría abajo, por otra parte, como ocurre, por ejemplo, con el Finnegan's Wake de Joyce, o incluso con buena parte de la música experimental, donde el caos barre directamente con el arte.

\section{REFERENCIAS}

BENJAMIN, Walter. O Narrador: considerações sobre a obra de Nikolai Leskov (1936). In: . Magia e técnica, arte e política: ensaios sobre literatura e história da cultura. São Paulo: Brasiliense, 1994. p. 197-221.

BLANCHOT, M. O espaço literário. Rio de Janeiro: Rocco, 2011.

BOLAÑO, R. El gaucho insufrible. Barcelona, Anagrama, 2001.

BOLAÑO, R. Entre paréntesis: ensayos, artículos y discursos (1998-2003). Barcelona: Anagrama, 2005.

DIDI-HUBERMAN, G. Diante do Tempo: história da arte e anacronismo das imagens. Tradução. de Alberto Pucheu. Paris: Minuit, 2000. Disponível em: $<$ http://revistapolichinelo.blogspot.com.br/2011/03/georges-didi-huberman. html>. Acesso em: 21 jun. 2014.

DIDI-HUBERMAN, G. Inquietar-se diante de cada imagem. Entrevista realizada por Mathieu Potte-Bonneville \& Pierre Zaoui. Revista Vacarme, n. 37, p. 4-12, 11 oct. 2006. Disponível em: <http://www.vacarme.org/article1210.html >. Tradução de Vinícius Nicastro Honesko. Disponível em: < http://flanagens.blogspot.com. br/2011/05/inquietar-se-diante-de-cada-imagem.html>. Acesso em: 12 maio 2014.

DIDI-HUBERMAN, G. Ante la imagen: pregunta formulada a los fines de uma história del arte. Múrcia: Cendeac, 2010.

FOUCAULT, M. L'arrière-fable. In: . Dits et écrits. Paris: Gallimard, 1994a. p. 506-513.

FOUCAULT, M. Distance, aspect, origine. In: . Dits et écrits. Paris: Gallimard, 1994b. p. 272-285.

FOUCAULT, M. Linguagem e literatura. In: MACHADO, R. A filosofia e a literatura. Rio de Janeiro: J. Zahar, 2000. p. 137-174 .

GOMPERTZ, W. Isso é arte? 150 anos de arte moderna. Rio de Janeiro: J. Zahar, 2013. 
MANGUEL, A. Lendo imagens. São Paulo: Companhia das Letras, 2011.

PELLEJERO, E. Política de autores y muerte del hombre: notas para una genealogía de la crítica cinematográfica. Sesión no numerada, Madrid, v. 2, p. 29-53, 2012.

PEREIRA, N. Modos de ler, formas de escrever: a literatura enquanto objeto da ficção de Enrique Vila-Matas. 2014. Dissertação (Mestrado)-Universidade Federal do Rio Grande do Norte, Natal, 2014.

RANCIÈRE, J. O espectador emancipado. Lisboa: Orfeu Negro, 2010.

ROSENBERG, H. Objeto ansioso. São Paulo: Cosac \& Naify, 2004.

SAER, J. J. La narración-objeto. Buenos Aires: Seix Barral, 1999.

SAER, J. J. El concepto de ficción. Buenos Aires: Seix Barral, 2004.

SAER, J. J. Trabajos. Buenos Aires: Seix Barral, 2006.

STEINER, G. Lenguaje y silencio: ensayos sobre la literatura, el lenguaje y lo inhumano. Barcelona: Gedisa, 2003.

VILA-MATAS, E. Chet Baker piensa en su arte. Barcelona: Debolsillo, 2011.

Recibido: 02 de julio 2014 Aceptado: 03 de septiembre 2014 